\title{
Role of Vitamin D-dependent and Vitamin D-independent Mechanisms in Absorption of Food Calcium
}

\author{
Mudassir S. Sheikh, Arnoldo Ramirez, Michael Emmett, Carol Santa Ana, Lawrence R. Schiller, and John S. Fordtran \\ Department of Internal Medicine, Baylor University Medical Center, Dallas, Texas 75246
}

\begin{abstract}
We measured net calcium absorption and the calcium content of the digestive glands secretions in people with widely different serum concentrations of 1,25 dihydroxy vitamin $D$ (hereafter referred to a 1,25-D). Patients with end stage renal disease on hemodialysis served as a model of human 1,25-D deficiency; they were also studied when they had abnormally high serum 1,25-D concentrations as a result of short periods of treatment with exogenous 1,25-D. Normal subjects were studied for comparison. The amount of calcium secreted into the duodenum by the digestive glands was found to be trivial compared to the calcium content of normal or even low calcium meals; therefore, values for net and true net calcium absorption differed only slightly. There was a linear correlation between true net calcium absorption and serum 1,25-D concentration. By extrapolating the short distance to a zero value for serum 1,25-D, D-independent true net calcium absorption was estimated. By subtracting $D$ independent from true net calcium absorption, values for D-dependent absorption were obtained. For a given level of meal calcium intake, D-dependent calcium absorption was found to be directly proportional to serum 1,25-D concentration. At any given value for serum 1,25-D, absorption via the D-dependent mechanism was approximately the same with a low (120 mg) calcium meal as it was when meal calcium intake was increased to $300 \mathrm{mg}$. We interpret this to mean that the D-dependent mechanism is saturated or nearly saturated by low calcium meals. The D-independent absorption/secretion mechanism resulted in secretion (a loss of body calcium in the feces) when intake was low (120 mg per meal) and absorption when intake was normal. All of the increment in calcium absorption that occurs when low or normal calcium meals are supplemented with extra calcium is mediated by the D-independent mechanism.
\end{abstract}

\section{Introduction}

Under experimental conditions, the intestine absorbs calcium by vitamin $D$-dependent and vitamin $D$-independent mechanisms. D-dependent absorption is an active carrier mediated process, whereas D-independent absorption or secretion is a passive response to electrochemical gradients $(1,2)$. The relative importance of $\mathrm{D}$-dependent and D-independent mecha-

Address reprint requests to Dr. Fordtran, Department of Internal Medicine, Baylor University Medical Center, 3500 Gaston Avenue, Dallas, TX 75246.

Received for publication 7 January 1987 and in revised form 26 August 1987.

J. Clin. Invest.

(c) The American Society for Clinical Investigation, Inc.

0021-9738/88/01/0126/07 \$2.00

Volume 81, January 1988, 126-132 nisms in the absorption of dietary calcium has not been previously determined, and the major purpose of the present series of studies was to provide insight into this question.

Patients with endstage kidney disease are not able to synthesize the active vitamin $\mathrm{D}$ metabolite, 1,25 dihydroxy vitamin $\mathrm{D}(1,25-\mathrm{D}),{ }^{1}$ and we have used such patients as a model of human vitamin $\mathrm{D}$ deficiency. Normal subjects and 1,25-D treated kidney failure patients were also studied, providing a wide range of serum 1,25-D concentrations. We assumed that $\mathrm{D}$ independent calcium absorption or secretion was the same, for a given calcium concentration grádient across the mucosa, in kidney failure patients as in normal subjects. This assumption is based on the fact that passive movement of calcium has been shown to be normal in 1,25-D-deficient dialysis patients (3) and also in vitamin D depleted experimental animals (4).

By plotting calcium absorption as a function of serum 1,25-D concentration, we were able to estimate the importance of D-independent and D-dependent mechanisms in the absorption of food calcium.

\section{Methods}

Definitions. Net calcium absorption is defined as calcium intake minus fecal calcium output. However, in response to a meal the extraintestinal digestive glands (salivary glands, stomach, liver, and pancreas) secrete fluids containing calcium. The calcium load to the intestine is therefore equal to dietary calcium intake plus calcium content of digestive secretions delivered into proximal duodenum. Calcium of endogenous origin can also gain entry into the gut lumen transintestinally through $(a)$ exchange diffusion that takes place across the intestinal wall, and $(b)$ passive secretion, when lumen calcium concentration is lower than that of plasma. These processes are part of the concept of net absorption and therefore not considered in the calcium load to the gut.

True net calcium absorption is equal to the calcium load to the intestine minus fecal calcium output. To calculate true net calcium absorption or secretion, calcium content of digestive secretions delivered into the duodenum is added to the net calcium absorption rate. The arithmetical validity of this calculation is evident from the following equations:

True net absorption $=\mathrm{Ca}$ load to gut - fecal output.

Since $\mathrm{Ca}$ load to gut $=$ dietary $\mathrm{Ca}$ intake $+\mathrm{Ca}$ in digestive secretions, true net absorption

$=($ dietary $\mathrm{Ca}$ intake $+\mathrm{Ca}$ in digestive secretions $)-$ fecal output.

Rearranging, true net absorption

$=($ dietary $\mathrm{Ca}$ intake - fecal output $)+\mathrm{Ca}$ in digestive secretions.

Since dietary intake - fecal output $=$ net absorption,

true net absorption $=$ net absorption $+\mathrm{Ca}$ in digestive secretions .

1. Abbreviations used in this paper: 1,25-D, 1,25 dihydroxy vitamin D. 
Subjects. Adult patients with chronic renal failure undergoing hemodialysis three times a week were studied. None were taking vitamin D preparations, and none had had nephrectomy or parathyroidectomy. All were medically stable, without clinical manifestations of bone disease or nutritional deficiency. The patients were studied as outpatients on a day of the week when they did not receive dialysis. Normal volunteers of similar age, sex, and race were also studied. Informed consent was obtained.

Duodenal content of calcium after ingestion of a very low calcium meal. Determination of true net calcium absorption requires knowledge of the calcium content of extraintestinal digestive glands secretions. Fortunately, all of these secretions are delivered into the duodenum (via either the pylorus or the ampulla of Vater), which is readily accessible by intubation. To estimate the amount of calcium secreted into the duodenum by the digestive glands, we fed subjects a meal containing only a very small amount of calcium and measured the calcium content of the duodenum. While for this purpose it would have been desirable to use a meal containing absolutely no calcium, such a meal would have to be synthetic and nonappetizing; it might not therefore evoke a physiological secretory response. The meal we used consisted of $140 \mathrm{~g}$ of ground sirloin steak, seasoned with salt and pepper, $100 \mathrm{~g}$ of french fried potatoes, and $250 \mathrm{ml}$ of water. For each experiment, duplicate meals were prepared, one to be fed to the subject and the other to be analyzed for calcium content. The calcium content of this meal was $\sim 17 \mathrm{mg}$.

Subjects were intubated with a double lumen tube, with openings that were $10 \mathrm{~cm}$ apart. Under fluoroscopic control, the proximal opening of the tube was located in the duodenum, at the normal location of the ampulla of Vater. Saline containing polyethylene glycol (PEG, a nonabsorbable volume marker) was infused through the proximal opening at a rate of $3 \mathrm{ml} / \mathrm{min}(180 / \mathrm{ml}$ per $\mathrm{h})$. After a 30 -min equilibration period (to establish steady state conditions) the meal was eaten, as the saline/PEG infusion continued. Fluid was aspirated through the distal opening at a rate of $1.5 \mathrm{ml} / \mathrm{min}$; from the PEG concentration in this fluid, the flow rate of fluid arriving at the distal sampling site was calculated by standard nonabsorbable marker equations (5). Calcium content was calculated by multiplying flow rate by the calcium concentration in the aspirated fluid. Fluid was collected for $6 \mathrm{~h}$, under the assumption that the meal stimulus to the digestive glands would be completed in $6 \mathrm{~h}$. Five dialysis patients were studied before and after treatment with oral 1,25-D capsules (Rocaltrol; Roche Laboratories, Nutley, NJ), $1.0 \mu \mathrm{g}$ twice a day for $9 \mathrm{~d}$. Five normal subjects were also studied. Blood for 1,25-D concentration was obtained before each experiment.

Calcium absorption. To measure net calcium absorption we used a one-meal method which has been described previously in detail (6). It begins with a preparatory lavage wherein the subject's entire gastrointestinal tract is cleansed by perfusion with a poorly absorbed solution. $4 \mathrm{~h}$ later the subject eats a meal, which includes $10 \mathrm{~g}$ of PEG as a nonabsorbable marker. $12 \mathrm{~h}$ after the meal, the intestine is cleansed again by a final perfusion. A duplicate meal and rectal effluent from the final perfusion are analyzed for calcium. The completeness of collection is evaluated by recovery of PEG. On a separate day, the entire procedure is repeated under fasting conditions, i.e., only water containing PEG is ingested; this provides an estimate of the amount of calcium in the rectal effluent due to the lavage procedure. It is important to emphasize that calcium in the lavage effluent after a fast does not reflect the amount of unabsorbed calcium from endogenous secretions; the lavage creates an electrochemical gradient favoring passive net diffusion of calcium from blood to gut lumen, and calcium in the effluent after a fast is due to the gradient imposed by the lavage (6). Net calcium absorption = meal calcium - (effluent calcium after meal - effluent calcium after fast). Previous studies have shown that the preliminary perfusion does not alter subsequent absorptive function and that all unabsorbed calcium is quantitatively recovered by the final perfusion (6).

Net calcium absorption was measured in four dialysis patients (three Black males, one White female; ages $38,44,49$, and $52 \mathrm{yr}$ ) and in five normal subjects (four Black males, one White female; ages 26, 37 , 38,47 , and 56). Before 1,25-D therapy, each dialysis patient was studied after a normal (300 mg) calcium meal, after a low $(120 \mathrm{mg})$ calcium meal, and after a fast. The order of tests was randomized. Patients were then treated with oral 1,25-D capsules (Rocaltrol), $1.0 \mu \mathrm{g}$ twice a day. After at least $9 \mathrm{~d}$ of treatment, the three tests (normal calcium meal, low calcium meal, and fast) were repeated. Blood for 1,25-D concentration was drawn before each meal. Normal subjects were studied on three test days (fast, normal calcium meal, and low calcium meal); the order of testing was randomized and blood for 1,25-D was drawn prior to one of the two meals. Normal subjects were not studied after 1,25-D therapy.

The normal $(300 \mathrm{mg})$ calcium meal consisted of $140 \mathrm{~g}$ of ground sirloin steak, seasoned with salt and pepper, $45 \mathrm{~g}$ of swiss cheese, $100 \mathrm{~g}$ of french fried potatoes, and $250 \mathrm{ml}$ of water containing $10 \mathrm{~g}$ of PEG. For the low $(120 \mathrm{mg})$ calcium meal the quantity of swiss cheese was reduced to $15 \mathrm{~g}$. For each experiment, duplicate meals were prepared, one to be fed to the subject and the other to be analyzed for calcium content.

Analysis of samples. PEG, which was used as a nonabsorbable marker, was analyzed by the method of Hyden (7). Calcium was analyzed by atomic absorption spectroscopy as described previously (6).

Serum concentration of 1,25-D was analyzed by Nichols Institute, San Juan Capistrano, CA, by a method described by Reinhardt et al. (8). Sensitivity of $<5 \mathrm{pg} / \mathrm{ml}$ is routinely achieved with $1 \mathrm{ml}$ of sample by this method. The assay is done in duplicate and mean result is reported. The intraassay and interassay variations for the assay are 9.3 and $12.2 \%$, respectively.

\section{Results}

Duodenal content of calcium after ingestion of a very low calcium meal. The results are shown in Table I. In normal subjects, the amount of calcium in the duplicate meal was $18 \pm 1$ $\mathrm{mg}$, and the amount of calcium arriving at the aspiration site in the duodenum was $29 \pm 4 \mathrm{mg}$ per $6 \mathrm{~h}$. Under these conditions, the average concentration of calcium in duodenal fluid was $1.3 \mathrm{mg} / \mathrm{dl}$ (range $0.5-2.2 \mathrm{mg} / \mathrm{dl}$ ). Since it is known from previous work $(3,9,10)$ that duodenal, jejunal, and ileal absorption/secretion of calcium is trivial when the small bowel is perfused with solutions containing calcium at these low levels, it seems reasonable to assume that there was minimal absorp-

Table I. Duodenal Calcium Content after Very Low Calcium Meal (Mean \pm SEM)

\begin{tabular}{lllll}
\hline & $\begin{array}{l}\text { Serum } \\
{[1,25-\mathrm{D}]}\end{array}$ & $\begin{array}{l}\text { Meal } \\
\mathrm{Ca}^{*}\end{array}$ & $\begin{array}{l}\text { Duodenal } \\
\mathrm{Ca} \text { content }\end{array}$ & $\begin{array}{l}\text { Duodenal } \\
\text { Ca conten } \\
- \text { meal Ca }\end{array}$ \\
\hline$p g / m l$ & $m g$ & $m g / 6 h$ & $m g / 6 h$
\end{tabular}

Normal subjects

$\begin{array}{lllll}(n=5) & 41 \pm 5 & 18 \pm 1 & 29 \pm 4 & 11 \pm 4\end{array}$

Dialysis patients

before $1,25-\mathrm{D}$

therapy $(n=5) \quad 5 \pm 2 \quad 16 \pm 2 \quad 39 \pm 6 \quad 23 \pm 7$

Dialysis patients

after 1,25-D

therapy $(n=5) \quad 91 \pm 18 \quad 16 \pm 1 \quad 27 \pm 5 \quad 10 \pm 5^{\ddagger}$

* Measured calcium content of duplicate meal.

${ }^{\ddagger} P<0.05$ by paired $t$ test compared to dialysis patients before 1,25 D therapy. 
tion or secretion in the short $(10 \mathrm{~cm})$ duodenal segment proximal to the aspiration site. Therefore, the amount of calcium secreted by the extraintestinal digestive glands can be estimated by subtraction (extraintestinal digestive glands secretions calcium $=$ duodenal calcium content - calcium content of the very low calcium meal). According to this method of calculation, the extraintestinal digestive glands secretions of normal subjects contained $11 \mathrm{mg}$ of calcium. In dialysis patients, who are severely deficient in $1,25-\mathrm{D}$, our calculations (Table I) show that digestive glands secretions into the duodenum contained $23 \mathrm{mg}$ of calcium (about twice the normal value). After treatment with $1,25-\mathrm{D}$, such secretions by dialysis patients contained $10 \mathrm{mg}$ of calcium $(P<0.05$ versus pretreatment values by paired $t$ test).

Thus, the extraintestinal digestive glands secretions contain only very small amounts of calcium, relative to the calcium content of normal or even low calcium diets, and secretions of the digestive glands contribute in only a small way to the load of calcium delivered to the intestine. Two possible reasons for the 13-mg higher average value in 1,25-D deficient dialysis patients are suggested in Discussion.

Calcium absorption. Mean values for serum 1,25-D concentration, the calcium content of the duplicate meal, and the recovery of calcium in the final perfusion effluent are shown in Table II. PEG recovery is not shown, but it varied from 98 to $101 \%$. Net calcium absorption can be calculated from this data, and the results are also shown in Table II. Net absorption was higher with the normal than with the low calcium meal, and with either meal varied in the same direction as the serum 1,25-D concentration.

True net calcium absorption can be calculated by adding the calcium content of extraintestinal digestive glands secretions to values for net calcium absorption. Since two of the dialysis patients and most of the normal subjects in whom net calcium absorption was measured were not able to be studied for duodenal calcium content, we do not have data on extraintestinal digestive glands secretions calcium in most of the subjects in whom net calcium absorption was measured. We therefore added the average value for extraintestinal digestive glands secretions calcium for the subjects studied in Table I to values for net calcium absorption in the individual subjects studied in Table II (11 mg added to net absorption in each normal subject, $23 \mathrm{mg}$ added for each untreated dialysis patient, and $10 \mathrm{mg}$ added for each 1,25-D-treated dialysis patient). Since the amount of calcium secreted by the extraintestinal digestive glands was negligible in comparison with values for net calcium absorption, values for net and true net absorption were only slightly different.

Fig. $1 A$ and $B$ show data in individual subjects for net and true net calcium absorption. There was a statistically significant linear relationship between serum 1,25-D concentration and net and true net calcium absorption (see Table III for correlation coefficients and $P$ values). The slopes of the regression lines for the normal and low calcium meals were similar. By extrapolating the regression lines for true net calcium absorption to zero serum 1,25-D concentration, values for D-independent true net calcium absorption or secretion ( $y$ intercepts) can be obtained. Defined in this way, vitamin D-independent true net calcium absorption was $32 \mathrm{mg}$ with the normal calcium meal and $-25 \mathrm{mg}$ (i.e., net secretion of $25 \mathrm{mg}$ ) with the low calcium meal.

By subtracting D-independent true net calcium absorption from the regression line for true net calcium absorption, a regression line for $\mathrm{D}$-dependent true net calcium absorption is obtained (Fig. $1 C$ ). There was a linear relationship between D-dependent absorption and serum 1,25-D concentration. By definition, the lines for the normal and low calcium meals have same slopes as corresponding lines in Fig. $1 B$, and like the regression lines in $B$ the two lines in $C$ have slightly different slopes that by statistical analysis are not significantly different. This suggests that the D-dependent absorption mechanism is already saturated (or nearly saturated) with the low calcium meal, and that increasing the amount of calcium available for absorption (by higher calcium meals) causes no (or only a slight) further increase in calcium absorption via this pathway.

Table II. Serum 1,25(OH) 2 Vitamin D Concentration and Net Calcium Absorption (Mean \pm SEM)

\begin{tabular}{|c|c|c|c|c|c|c|c|c|c|}
\hline & \multicolumn{2}{|c|}{ Serum $[1,25-D]$} & \multirow{2}{*}{$\begin{array}{l}\text { Effluent } \\
\text { Ca after } \\
\text { fast* }\end{array}$} & \multicolumn{3}{|c|}{ Normal calcium meal } & \multicolumn{3}{|c|}{ Low calcium meal } \\
\hline & $\begin{array}{l}\text { Normal } \\
\text { Ca meal }\end{array}$ & $\begin{array}{l}\text { Low Ca } \\
\text { meal }\end{array}$ & & $\begin{array}{l}\text { Meal } \\
\mathrm{Ca}^{\ddagger}\end{array}$ & $\begin{array}{l}\text { Effluent } \\
\mathrm{Ca}\end{array}$ & $\begin{array}{l}\text { Net } \\
\text { absorption }\end{array}$ & $\begin{array}{l}\text { Meal } \\
\mathrm{Ca}^{\ddagger}\end{array}$ & $\begin{array}{l}\text { Effluent } \\
\mathrm{Ca}\end{array}$ & $\begin{array}{l}\text { Net } \\
\text { absorption }\end{array}$ \\
\hline & $\mathrm{pg} / \mathrm{ml}$ & $\mathrm{pg} / \mathrm{ml}$ & $m g$ & $m g$ & $m g$ & $m g$ & $m g$ & $m g$ & $m g$ \\
\hline \multicolumn{10}{|l|}{ Normal subjects } \\
\hline \multicolumn{10}{|l|}{$\begin{array}{c}\text { Dialysis patients } \\
\text { before } 1,25-\mathrm{D}\end{array}$} \\
\hline therapy $(n=4)$ & $9 \pm 1$ & $7 \pm 1$ & $59 \pm 3$ & $301 \pm 1$ & $317 \pm 31$ & $43 \pm 31$ & $119 \pm 1$ & $205 \pm 4$ & $-26 \pm 4^{\prime \prime}$ \\
\hline \multicolumn{10}{|l|}{$\begin{array}{l}\text { Dialysis patients } \\
\text { after } 1,25-\mathrm{D}\end{array}$} \\
\hline therapy $(n=4)$ & $84 \pm 13$ & $66 \pm 12$ & $49 \pm 7$ & $301 \pm 1$ & $176 \pm 33$ & $175 \pm 40$ & $118 \pm 3$ & $79 \pm 11$ & $88 \pm 15$ \\
\hline
\end{tabular}

* The calcium content of the lavage effluent after a fast is due to the lavage procedure per se, as described in Methods. ${ }^{\ddagger}$ Measured calcium content of duplicate meal. ${ }^{\S}$ Net absorption $=$ meal $\mathrm{Ca}$ - [effluent $\mathrm{Ca}$ after meal - effluent Ca after fast]. "Minus sign denotes net secretion. $P$ values for net calcium absorption: Normal Ca meal: normal subjects vs. dialysis patients before $1,25-\mathrm{D}$ therapy ${ }^{\dagger}$, NS; normal subjects vs. dialysis patients after $1,25-\mathrm{D}$ therapy ${ }^{\dagger}$, NS; dialysis patients before vs. after $1,25-\mathrm{D}$ therapy ${ }^{\dagger+}, P<0.005$. Low Ca meal: normal subjects vs. dialysis patients before $1,25-\mathrm{D}$ therapy ${ }^{\dagger}, P<0.05$; normal subjects vs. dialysis patients after $1,25-\mathrm{D}$ therapy ${ }^{\dagger}$, NS; dialysis patients before vs. after 1,25-D therapy ${ }^{\dagger+}, P<0.01 .{ }^{\dagger}$ Group $t$ test, ${ }^{\dagger t}$ paired $t$ test. 


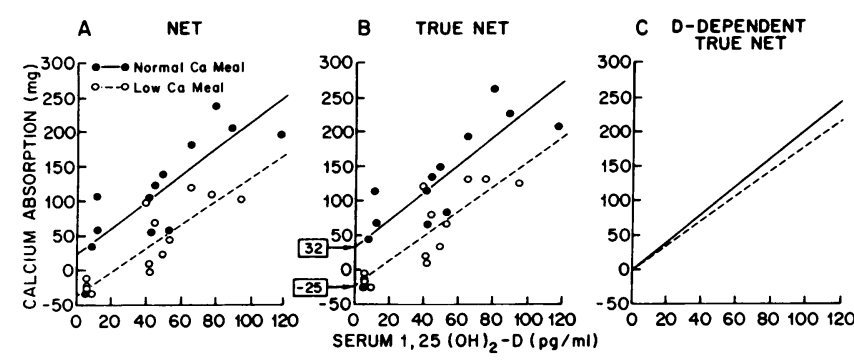

Figure 1. Correlation of calcium absorption and serum $1,25(\mathrm{OH})_{2}$ D $(1,25-D)$ concentration in individual subjects. $A$ shows net absorption. The slopes for the regression lines for the normal and low calcium meal are statistically not different $(P=0.758)$. $B$ shows true net absorption. The slopes of regression lines for true net calcium absorption for normal and low calcium meals are also statistically not different $(P=0.757)$. By extrapolation to zero $1,25-\mathrm{D}$ concentration (arrows), estimates of D-independent true net absorption are derived. $C$ shows D-dependent true net absorption derived from $B$ by subtracting D-independent true net absorption from regression lines for true net absorption. The slopes of these two lines are same as of the corresponding lines in $B$.

If normal subjects are excluded from above analysis and only the data from dialysis patients (before and after 1,25-D therapy) are used, regression lines very similar in intercepts and slopes to those shown in Fig. 1 are obtained. This is shown in Table III. In other words. the normal subjects fit nicely in the regression lines obtained from dialysis patients, without significantly changing the intercepts or slopes.

The relative contribution of D-independent and D-dependent processes to true net calcium absorption or secretion (using combined data from normal subjects and dialysis patients) is shown in Fig. 2 for untreated dialysis patients, for

Table III. Intercepts, Slopes, and Correlation Coefficients of Regression Lines for Calcium Absorption vs. Serum 1,25-D Levels

\begin{tabular}{llll}
\hline Intercept & Slope & $\begin{array}{l}\text { Correlation } \\
\text { coefficient }\end{array}$ \\
\hline $\mathrm{mg}$ & $\mathrm{mg} / \mathrm{pg} / \mathrm{ml}$
\end{tabular}

A Normal subjects and dialysis patients

Net Ca absorption

Normal Ca meal

Low Ca meal

$24 \quad 1.88$

$0.81, P<0.001$

True net $\mathrm{Ca}$ absorption*

Normal Ca meal

$-34$

1.71

$0.85, P<0.001$

Low Ca meal

32

2.02

0.83, $P<0.001$

B Dialysis patients only ${ }^{\ddagger}$

Net Ca absorption

$$
-25
$$

1.85

$0.86, P<0.001$
Normal Ca meal

24

$-28$

Normal Ca meal

Low Ca meal
True net Ca absorption*
1.81

1.63

1.96

1.81
$0.83, P<0.002$

$0.90, P<0.005$

$0.85, P=0.008$

$0.91, P=0.002$
* Slopes and correlation coefficient values for D-dependent true net $\mathrm{Ca}$ absorption are identical to those for true net $\mathrm{Ca}$ absorption.

${ }^{\ddagger}$ Intercepts and slopes for normal subjects and dialysis patients $(A)$ are not statistically different from corresponding values for dialysis patients only $(B)$.

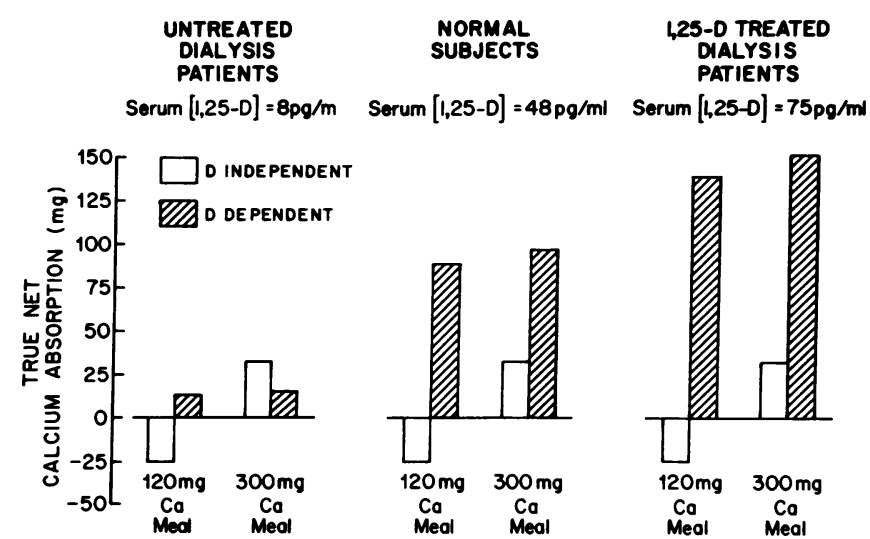

Figure 2. Relative contribution of D-independent and D-dependent mechanisms to true net calcium absorption in the three groups of subjects studied. Values of D-independent true net calcium absorption are obtained from Fig. $1 \mathrm{~B}$. Values for D-dependent true net calcium absorption are obtained from Fig. $1 C$ for average serum 1,25D concentrations of the three groups of subjects.

normal subjects, and for 1,25-D treated dialysis patients. D-independent calcium absorption is $-25 \mathrm{mg}$ (secretion) with the low calcium meal and $32 \mathrm{mg}$ with the normal calcium meal (obtained from Fig. $1 \mathrm{~B}$ ); for reasons explained in the Introduction, the same values apply to all three groups of subjects, regardless of serum 1,25-D concentration. Values for D-dependent absorption for the three groups are obtained from Fig. $1 C$, using average serum 1,25-D concentrations for each group. D-dependent calcium absorption was approximately the same for low and normal calcium meals, and was higher in normal subjects than in untreated dialysis patients, and higher in 1,25-D treated dialysis patients than in normal subjects. As is evident from the data in this figure, the relative contribution of D-independent and D-dependent processes to overall absorption varies greatly with $1,25-\mathrm{D}$ status and with the amount of calcium ingested in the meal.

Comparison of observed and predicted calcium asorption. If our conclusions in the previous section are valid, we should be able to predict calcium absorption from normal or high calcium meals if serum 1,25-D concentration is known. The degree to which such predictions agree with observed absorption is therefore a test of the validity of our conclusions.

Predicted calcium absorption is the sum of predicted Ddependent and D-independent absorption. Predicted D-dependent absorption, for any given 1,25-D concentration, is obtained from Fig. $1 C$; since D-dependent absorption is saturated by even low calcium meals, absorption by this mechanism is not dependent on calcium intake so long as more than $120 \mathrm{mg}$ of calcium is ingested. According to our analysis in the previous section, D-independent calcium absorption increased from -25 to $32 \mathrm{mg}$ as meal calcium intake increased from 121 to $302 \mathrm{mg}$ (Fig. $1 \mathrm{~B}$ ). Thus increasing intake by $181 \mathrm{mg}$ increased D-independent absorption by $57 \mathrm{mg}$, or $31 \mathrm{mg}$ per 100 $\mathrm{mg}$ increment in meal calcium intake. Since D-independent absorption is passive and nonsaturable, absorption via this mechanism should increase by $31 \mathrm{mg}$ for each $100-\mathrm{mg}$ increment in meal calcium intake. Therefore, knowing $D$ independent absorption for 120- and 300-mg calcium meals, we can predict D-independent absorption from meals by any calcium content. For example, for a meal containing $400 \mathrm{mg}$ of cal- 
cium, D-independent calcium absorption is predicted to be 32 $\mathrm{mg}$ (the value for a $300-\mathrm{mg}$ calcium meal) plus $31 \mathrm{mg}$ (for the $100 \mathrm{mg}$ increment in intake) or $63 \mathrm{mg}$.

In groups of healthy young subjects (White seminary students, age 25-30) and dialysis patients, none of whom were used in previous sections of this paper, we measured net calcium absorption after meals containing widely different amounts of calcium. Serum 1,25-D concentration was measured, and calcium absorption was predicted by the methods described in the previous paragraph. Average serum 1,25-D concentration in these White healthy young subjects was somewhat lower than in older mainly Black controls studied for the previous section; this may perhaps be due to higher milk (and calcium) consumption in White as compared with Black subjects. As can be seen in Table IV and Fig. 3, there was excellent agreement between measured and predicted absorption $(r=0.989, P<0.001)$.

\section{Discussion}

To estimate the relative importance of D-independent and D-dependent processes in the absorption of dietary calcium, several requirements had to be met. First, we needed to measure net absorption in people with different serum concentrations of 1,25 dihydroxy vitamin $\mathrm{D}$ (hereafter referred to as 1,25-D). For this purpose, we studied patients with end stage renal disease undergoing hemodialysis (when they had extremely low serum concentrations of 1,25-D), and after treatment with 1,25-D in a dose that caused their serum 1,25-D concentrations to be about twice the normal value. Normal subjects were also studied, providing a third group with an average serum 1,25-D concentration that was about midway between that of the two dialysis groups.

Second, we needed a method for measuring net absorption or secretion of calcium after ingestion of normal foods, and the method had to be applicable to outpatients on dialysis therapy. For this, we used a technique wherein net gastrointestinal absorption or secretion of food constituents can be measured after ingestion of a single meal (6). Calcium, phosphorus, and caloric absorption in normal people by this method are similar to values obtained with the prolonged balance method $(6$, 11-13).

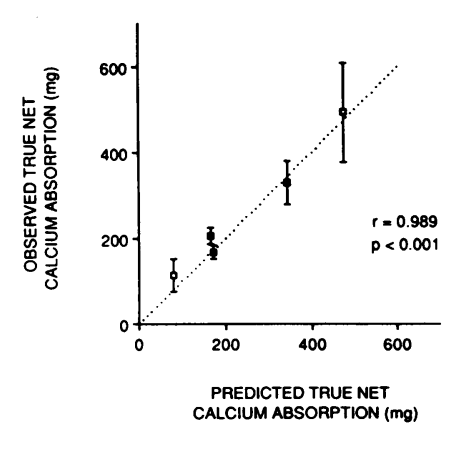

Figure 3. Correlation of true net calcium absorption predicted from Fig. 1 to true net calcium absorption observed in groups of young healthy subjects ( $\square$ ) and 1,25-D-deficient dialysis patients ( $\square$ ). Details of prediction are shown in Table IV.

Third, we needed to estimate calcium secretion into the duodenum by the extraintestinal digestive glands (pancreas, liver, etc.), since such secretions (evoked by a meal) contribute to the load of calcium presented to the intestine following the ingestion of food. This quantity must be considered if true net calcium absorption or secretion by the intestine is to be assessed. To obtain this information, we used an intubation and nonabsorbable marker technique, and measured duodenal calcium content after a very low calcium meal was eaten. By subtracting the small amount of calcium in the very low calcium meal from the duodenal calcium content, we estimated the amount of calcium secreted into the duodenum by the digestive glands.

Fourth, we needed to vary the calcium load to the duodenum, and to do this we studied the three groups of subjects after they had eaten meals containing either 120 or $300 \mathrm{mg}$ of calcium. If similar foods were eaten three times a day, these meals would conform respectively to a low calcium diet (360 $\mathrm{mg} / \mathrm{d})$ and a normal calcium diet $(900 \mathrm{mg} / \mathrm{d})$. The latter amount is close to the recommended daily allowance of 800 $\mathrm{mg}$ of calcium for adults by the U. S. Food and Nutrition Board.

We found that the digestive secretions delivered into the duodenum contained trivial amounts of calcium in comparison to the amount of calcium in normal or even low calcium diets. Thus, the secretions of the digestive glands contribute in only a minor way to the load of calcium delivered to the intestine, and as a result true net calcium absorption is only slightly higher than net calcium absorption. We did find, however,

Table IV. Predicted and Observed Calcium Absorption

\begin{tabular}{|c|c|c|c|c|c|c|c|c|}
\hline \multirow[b]{2}{*}{ Subjects } & \multirow[b]{2}{*}{$n$} & \multirow[b]{2}{*}{ Serum $1,25-D$} & \multirow[b]{2}{*}{ Main Ca source } & \multirow[b]{2}{*}{$\begin{array}{l}\text { Ca } \\
\text { intake }\end{array}$} & \multicolumn{3}{|c|}{ Predicted true net absorption } & \multirow{2}{*}{$\begin{array}{l}\text { Observed } \\
\text { true net } \\
\text { absorption }\end{array}$} \\
\hline & & & & & $\begin{array}{l}\mathrm{D} \\
\text { dependent }\end{array}$ & $\begin{array}{l}\mathrm{D} \\
\text { independent }\end{array}$ & Total & \\
\hline & & $p g / m l$ & & $m g$ & $m g$ & $m g$ & $m g$ & $m g$ \\
\hline Dialysis patients & 5 & $7 \pm 2$ & Swiss cheese & 405 & 14 & 65 & 79 & $114 \pm 38$ \\
\hline Dialysis patients & 5 & $7 \pm 2$ & $\begin{array}{l}\text { Swiss cheese } \\
+ \text { Ca carbonate }\end{array}$ & 1666 & 14 & 461 & 475 & $493 \pm 116$ \\
\hline Healthy young subjects & 8 & $36 \pm 2$ & Milk & 513 & 73 & 99 & 172 & $168 \pm 17$ \\
\hline Healthy young subjects & 8 & $35 \pm 2$ & Ca carbonate & 502 & 70 & 95 & 165 & $206 \pm 18$ \\
\hline Healthy young subjects & 9 & $\ddagger$ & Ca carbonate & 1071 & 72 & 274 & 346 & $329 \pm 50$ \\
\hline
\end{tabular}

* Observed true net $\mathrm{Ca}$ absorption is calculated by adding Ca content of digestive secretions ( $23 \mathrm{mg}$ for dialysis patients, and $11 \mathrm{mg}$ for normal subjects, from Table I) to observed net $\mathrm{Ca}$ absorption. ${ }^{\ddagger}$ Serum 1,25-D not measured but assumed to be same as average measured level of other healthy young subjects. 
that the calcium content of extraintestinal digestive glands secretions was $13 \mathrm{mg}$ higher in 1,25-D deficient than in 1,25-Dtreated dialysis patients. There would appear to be two possible explanations for this observation: $(a)$ The $10-\mathrm{cm}$ duodenal segment proximal to our collection site absorbs or secretes some calcium under these experimental conditions, the rate of such absorption/secretion being dependent on serum 1,25-D concentration. For example, 1,25-D treated patients might absorb a small amount of calcium in the duodenal segment, whereas untreated dialysis patients might secrete a small amount, giving rise to the 13-mg difference. (b) 1,25-D inhibits calcium secretion by the digestive glands, perhaps by stimulating ductal reabsorption of calcium secreted by liver and pancreatic parenchymal cells. We have no way of knowing which explanation is correct. However, this uncertainty does not detract from our main finding, that digestive glands secretions into the duodenum contain only very small amounts of calcium, regardless of $1,25-\mathrm{D}$ status. This finding is consistent with earlier estimates of the amount of calcium secreted into duodenum of normal subjects in response to maximal hormonal stimulation by cholecystokinin and secretin (14-16).

Our estimate of the calcium content of extraintestinal digestive glands secretions is considerably less than the "endogenous calcium secretion" that has been calculated by others using radioactive isotopes of calcium (17). Such calculations have been interpreted to mean that $\sim 200 \mathrm{mg}$ endogenous calcium is secreted into the gut each day $(66 \mathrm{mg} / \mathrm{meal})$. This value is six times higher than the amount of calcium we estimate is secreted by digestive glands into the duodenum per day if three meals were eaten by normal subjects. However, it should be noted that "endogenous calcium secretion" is dependent on the amount of intravenously injected calcium isotope that appears in feces. An intravenously injected calcium isotope can gain access to the feces via several routes in addition to secretions by the extraintestinal digestive glands, including exchange diffusion across the tight junctions of epithelial cells along the entire length of the intestinal tract. To the extent that an intravenously injected radioactive calcium ion enters the gut lumen in exchange for a nonradioactive calcium ion in the lumen that moves into plasma, there is no net transfer of calcium into the intestinal lumen. This would however contribute to the radioactivity in feces, thereby giving falsely high estimate of net calcium secretion into gut lumen. Thus, it is not surprising that "endogenous calcium secretion" is measured by isotopic methods is higher than our direct estimate of the calcium content of the digestive secretions. Only the latter is pertinent to calculation of the calcium load to the intestine and true net calcium absorption (as explained in Methods).

Having measured net calcium absorption and the amount of calcium secreted by the extraintestinal digestive glands, true net calcium absorption could be calculated. True net calcium absorption was then plotted as a function of serum 1,25-D concentration, and a linear correlation was found, with $r$ values of 0.83 and 0.86 for the two meals (Table III). The fact that the intercepts and slopes of these lines were similar with or without the normal subjects (see Table III) supports the concept (outlined in the Introduction) that normal subjects and dialysis patients differ only in 1,25-D status insofar as calcium absorption is concerned.

The linear correlation of calcium absorption and serum 1,25-D concentration allowed us to estimate D-independent absorption by extrapolating the short distance to a zero value for serum 1,25-D. By this method, we calculated that D-independent true net calcium absorption increased from -25 to 32 $\mathrm{mg}$ as meal calcium increased from 121 to $302 \mathrm{mg}$. Thus, increasing intake by $181 \mathrm{mg}$ increased D-independent absorption by $57 \mathrm{mg}$, or $31 \mathrm{mg}$ per $100 \mathrm{mg}$ increment in meal calcium intake. This relationship should prevail for any increment in calcium intake since D-independent absorption is passively mediated, nonsaturable, and hence linearly correlated with luminal calcium concentration which in turn is dependent upon calcium intake.

By subtracting D-independent from observed true net calcium absorption a regression line for D-dependent true net calcium absorption as a function of serum 1,25-D concentration was obtained. This analysis revealed that D-dependent true net calcium absorption increased in proportion to serum $1,25-\mathrm{D}$ concentration. Moreover, the slopes of regression lines for this relationship were statistically not different $(P=0.757)$ with the 120 - and $300-\mathrm{mg}$ calcium meals. In other words, there was a slight but not significant increase in $\mathrm{D}$-dependent absorption as dietary calcium intake was increased from 120 to $300 \mathrm{mg}$ per meal. We interpret this to mean that the D-dependent calcium absorption mechanism is saturated (or nearly so) by the low calcium meal, and that increasing the amount of calcium available for absorption causes no significant increase in calcium absorption via this pathway.

To evaluate the extent to which these conclusions are quantitatively accurate, we compared absorption of calcium observed in groups of normal and dialysis subjects with calcium absorption predicted from the data in Fig. 1. Predicted absorption, based on the sum of predicted D-dependent and D-independent absorption was closely correlated with observed calcium absorption $(r=0.989, P<0.001)$, supporting the validity of our conclusions.

The relative importance of D-independent and D-dependent mechanisms of calcium absorption is evident from Fig. 2. For 1,25-D-deficient dialysis patients, the D-independent pathway plays a critical role, where it is responsible for a loss of calcium from the body (secretion) when calcium intake is low, and where it mediates a small amount of calcium absorption when calcium intake is normal. Being the passive consequence of electrochemical gradients across the intestinal mucosa, Dindependent calcium absorption should increase linearly with increasing calcium intake. Therefore, the D-independent pathway should be able to result in a normal amount of calcium absorption in 1,25-D-deficient people if calcium intake is increased to high enough values. That this is so is evident from Table IV, which shows that 1,25-D-deficient dialysis patients absorbed almost $500 \mathrm{mg}$ of calcium when meal calcium intake was high.

Even though the D-dependent pathway is saturated by relatively low calcium meals, in normal people (normal serum 1,25-D concentration) eating a normal calcium diet the D-dependent mechanism is dominant, accounting for almost three times more calcium absorption than the D-independent pathway. The relative importance of $\mathrm{D}$ dependent absorption is even greater when normal calcium meals are eaten by people whose serum concentration of $1,25-\mathrm{D}$ is higher than normal, as is evident from the results shown in Fig. 2.

Average daily calcium intake varies widely in different parts of the world, for example: United States, 1,000 mg; Venezuela, $865 \mathrm{mg}$; India $469 \mathrm{mg}$; and Japan $384 \mathrm{mg}$ (18). The 
body adapts to a low calcium diet by increasing renal synthesis of 1,25-D. However, the extent to which serum 1,25-D concentration is increased by a low calcium diet has not been studied extensively in humans. In one experiment (19), normal American subjects had a 1.6 -fold increase in average serum 1,25-D concentration when they ate a diet containing $\sim 200 \mathrm{mg} / \mathrm{d}$ of calcium for $4 \mathrm{wk}$, as compared to when they ate a diet containing $\sim 1,900 \mathrm{mg}$ of calcium/d. We have been unable to find any studies showing the effects on serum 1,25-D of low calcium diets for longer periods of time, nor could we find serum 1,25-D values for people on prolonged low calcium diets who live in India or Japan. However, if people who chronically subsist on a low calcium diet $(360 \mathrm{mg} / \mathrm{d}$, for example, which corresponds to our low calcium meal of $120 \mathrm{mg}$ ) have serum 1,25-D concentration of $75 \mathrm{pg} / \mathrm{ml}$, they could absorb almost as much calcium from their low calcium diet as do people who eat $\sim 900 \mathrm{mg}$ of calcium/d and have serum 1,25D concentrations of $48 \mathrm{pg} / \mathrm{ml}$ (this conclusion is evident from the data in Fig. 2).

As has been pointed out, our data indicate that calcium absorption mediated by the $\mathrm{D}$-dependent mechanism is already saturated by the low calcium meal. This implies that all of the increment in calcium absorption that occurs when a normal or even a low calcium diet is supplemented with extra calcium is mediated by the D-independent mechanism. Since this mechanism for calcium absorption is not saturable and can mediate substantial calcium absorption by itself, the logic, cost effectiveness and safety of adding vitamin $\mathrm{D}$ to calcium supplements may need to be reexamined.

\section{Acknowledgments}

The authors wish to thank Janie Francis and Marcia Horvitz for their help in preparing the manuscript.

This work was supported by U. S. Public Health Service grant 1-ROI-AM-26794 from the National Institute of Arthritis, Metabolism, and Digestive Diseases and a grant from the David Bruton, Jr. Trust.

\section{References}

1. Schachter, D., and S. M. Rosen. 1959. Active Transport of $\mathrm{Ca}^{45}$ by the small intestine and its dependence on vitamin D. Am. J. Physiol. 196(2):357-362.

2. Pansu, D., C. Bellaton, C. Roche, and F. Bronner. 1983. Duodenal and ileal calcium absorption in the rat and effects of vitamin $D$. Am. J. Physiol. 244:G695-G700.

3. Parker, T. F., P. Vergne-Marini, A. R. Hull, C. Y. C. Pak, and
J. S. Fordtran. 1974. Jejunal absorption and secretion of calcium in patients with chronic renal disease on hemodialysis. J. Clin. Invest. 54:358-365.

4. Halloran, B. P., and H. F. DeLuca. 1980. Calcium transport in small intestine during early development: Role of vitamin D. Am. J. Physiol. 239:G473-G479.

5. Fordtran, J. S., R. Levitan, V. Bikerman, B. A. Burrows, and F. J. Ingelfinger. 1961. The kinetics of water absorption in the human intestine. Trans. Assoc. Am. Phys. 74:195-205.

6. Bo-Linn, G. W., G. R. Davis, D. J. Buddrus, S. G. Morawski, C. A. Santa Ana, and J. S. Fordtran. 1984. An evaluation of the importance of gastric acid secretion in the absorption of dietary calcium. J. Clin. Invest. 73:640-647.

7. Hyden, S. A. 1955. Turbidometric method for determination of higher polyethylene glycols in biological materials. Lantbrukshogsh Ann. 22:139-145.

8. Reinhardt, T. A., R. L. Horst, J. W. Orf, and B. W. Hollis. 1984. A microassay for 1,25 -dihydroxy vitamin $\mathrm{D}$ not requiring high performance liquid chromatography. Application to clinical studies. $J$. Clin. Endocrinol. Metab. 58:91-98.

9. Wensel, R. H., C. Rich, A. C. Brown, and W. Volwiler. 1969. Absorption of calcium measured by intubation and perfusion of the intact human small intestine. J. Clin. Invest. 48:1768-1775.

10. Vergne-Marini, P., T. F. Parker, C. Y. C. Pak, A. R. Hull, H. F. DeLuca, and J. S. Fordtran. 1976. Jejunal and ileal calcium absorption in patients with chronic renal disease. J. Clin. Invest. 57:861-866.

11. Ramirez, J. A., M. Emmett, M. G. White, N. Fathi, C. A. Santa Ana, S. G. Morawski, and J. S. Fordtran. 1986. The absorption of dietary phosphorus and calcium in hemodialysis patients. Kidney Int. 30:753-759.

12. Bo-Linn, G. W., C. A. Santa Ana, S. G. Morawski, and J. S. Fordtran. 1982. Starch blockers: their effect on caloric absorption from a high-starch meal. N. Engl. J. Med. 307:1413-1416.

13. Bo-Linn, G. W., C. A. Santa Ana, S. G. Morawski, and J. S. Fordtran. 1983. Purging and caloric absorption in bulimic patients and normal women. Ann. Intern. Med. 99:14-17.

14. Hansky, J. 1967. Calcium content of duodenal juice. Am. J. Dig. Dis. 12:725-733.

15. Regan, P. T., Malagelada, J. R., and E. P. DiMango. 1980. Duodenal calcium outputs in health and disease. Gut. 21:614-618.

16. Lohse, J., and A. Pfeiffer. 1984. Duodenal total and ionized calcium secretion in normal subjects, chronic alcoholics, and patients with various stages of chronic alcoholic pancreatitis. Gut. 25:874-880.

17. Heaney, R. P., and T. G. Skillman. 1964. Secretion and excretion of calcium by the human gastrointestinal tract. J. Lab. Clin. Med. 64:29-41.

18. Calcium Requirements. Report on an FAO/WHO expert group. 1962. WHO Tech. Rep. Series 230, Rome FAO.

19. Norman, D. A., J. S. Fordtran, L. J. Brinkley, J. E. Zerwekh, M. J. Nicar, S. M. Strowig, and C. Y. C. Pak. 1981. Jejunal and ileal adaptation to alterations in dietary calcium. J. Clin. Invest. 67:15991603. 